Krahl and Clowes (1938).-Jl. Cell. and Comp. Physiol., Vol. XI, pp. I, 21. KRAMER (1920).-Jl. Biol. Chem., Vol XLI, p. 263.

KUTz (1931). - Jl. Biol. Chem., Vol. XCII, Proceedings, p. 72.

Lillie, Hinrichs and Kosman (1935).-Jl. Cell. and Comp. Physiol., Vol. VI, p. 487.

Lythgoe and Quilliam (1938).-Jl. Physiol., Vol. XCIII, p. 24.

MeYer and PALMer (1936).-Jl. Biol. Chem., Vol. CXIV, p. 689.

(1937).-Ibid., Vol. CXVIII, p. 71:

MEYER, DUBOS and SMYTH (1937). -Ibid, Vol. CXVIII, p. 71.

Monukova and FRADKIN (1935).-Arch.f. Ophthal., Vol. CXXXIII, p. 328.

MÜlle R (1932).-Ber. Ophthal. Ges., Leipzig. Vol. XLIX, p. 168.

- (1933).-Arch.f. Augenheilk., Vol. CVIII, p. 41.

- (1935-6).-Ibid., Vol. CIX, pp. 304, 434, 497.

(1937). Ibid., Vol. CX, p. 321.

MÜLleR and BuschKe (1934).-Arch. f. Augenheilk., Vol. CVIII, pp. 368, 597

ROBERTSON (1938).-Lancet, Vol. I, p. 1435.

L (1939).-Brit. Jl. Ophthal., Vol. XXIII, pp. 106, 170, 243.

SEN DROY (1937).-Jl. Biol. Chem., Vol. CXX, p. 335.

STARY and WINTERNITZ (1932).-Zeitschr. $f$. Physiol. Chem., Vol. CCXII, p. 215.

TYLER and Horowitz (1937).-Proc. Nat. Acad. Sci., Vol. XXIII, p. 369.

VAN SLYKE (1926). - Factors Affecting the Distribution of Electrolytes. Water and Gases in the Animal Body. Philadelphia.

VAN Sly Ke (1923).-Jl. Biol. Chem., Vol. LVIII, p. 523.

WALKER (1933).- Jl. Biol. Chem., Vol. CI, p. 269.

\title{
EXPERIMENTS ON THE EFFECT OF ASCORBIC ACID IN MUSTARD GAS BURNS OF THE EYE
}

BY

IDA MAN and B. D. Pullinger

LONDON

A stimulating article by Livingston and Walker ${ }^{1}$ appeared recently on the effects of mustard gas $\left(\beta \beta^{\prime}\right.$ di-chloro-diethylsulphide) on the eyes of rabbits and the results of certain forms of treatment. The authors stated that they had not reached any final conclusion as to the value of local applications in treatment, but that their results at present pointed to the probability that local therapy would have little, if any, effect, and that the only procedure likely to prove of value would be the intravenous or parenteral injection of some substance which might prevent or counteract the peculiar chemical and physical effects of mustard gas on the cornea. They made use of ascorbic acid for this purpose and gave an account of their preliminary experiments, which suggested that this substance might be of value. The time at their disposal had been too short to arrive at a final conclusion, but the importance of the subject justified publication of the results so far achieved. The present research has been done in response to an invitation from the authors of the paper mentioned above to repeat their experiments.

Two problems among those in need of further enquiry emerge 
from the paper referred to. Firstly, was the apparent resistance of some of the animals due to individual variations or to slight differences of dosage dependent on the method of application of the gas? Secondly, we question whether the period of observation after treatment with ascorbic acid was long enough to judge if the cornea derived as much protection as was claimed for the lids and conjunctivae. The first point was answered by experiments on a series of rabbits; in some the dose of mustard gas to the eyes was carefully measured and was exactly the same (Exp: III), in others an applicator was used and the dose it delivered was assumed to be always the same (Exps. I and II), but was not accurately measurable. Some of the rabbits were treated with ascorbic acid and others were not. All were kept alive and have been examined for from six to twelve weeks up to the date of writing in order to obtain an answer to the second problem, namely, the degree of protection, if any, of the cornea. The eyes were observed with a corneal loupe, a slit-lamp and a binocular-dissecting microscope.

\section{Experiment I. See Table I}

\section{Application of a minute unmeasured dose in untreated rabbits}

On March 22, 1940, eleven eyes of six young rabbits received doses of mustard gas. The lids were held back by a lid retractor for 15 minutes from the time of application of the liquid gas.* The liquid was put on with a glass applicator. This was a solid rod drawn out to a short fine end on the tip of which a small round bead $0.25 \mathrm{~mm}$. in diameter was made. The same tool was used on every eye in this group. It was dipped into the liquid and immediately placed gently on the cornea. Applications were made in the form of multiple spots along the limbs of a sector of the eye, thus :-

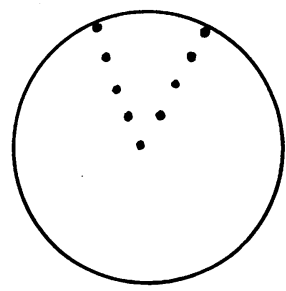

Nine of these small doses were put on to each of the eleven eyes. The twelfth eye was used to observe the effect of the

* This does not introduce any extraneous factor as the average normal blinking interval in rabbits is more than twenty minutes. 
applicator alone. The assumption was made and later proved to be false, that each spot and each eye received the same dose. Fifteen minutes after this treatment the lids were allowed to close. This particular time interval was chosen because Livingston and Walker had found that no irritant substance remained in the conjunctival sac 15 minutes after putting the liquid on the eye. By this means it proved possible to keep lids and conjunctivae relatively free from swelling and discharge so that detailed observation of the cornea could be made. No systemic or local treatment was given other than removal of discharge once daily with

Table I. Experiment I. Mustard Gas alone

Figures refer to the number of eyes affected out of 11

\begin{tabular}{|c|c|c|c|c|c|c|c|}
\hline \multirow{2}{*}{ LESIONS } & \multicolumn{7}{|c|}{ DAYS OF DISEA } \\
\hline & One & Two & Three & Four & Five & Six & Seven \\
\hline $\begin{array}{l}\text { Conjunctivitis with } \\
\text { or without muco } \\
\text { purulent discharg }\end{array}$ & h & 9 & 6 & 7 & 6 & 3 & 3 \\
\hline $\begin{array}{l}\text { Swelling (hyperae } \\
\text { mia and oedema) } \\
\text { lids }\end{array}$ & - & 5 & 4 & 2 & 1 & 0 & 0 \\
\hline CORNEA: & & & & & & & \\
\hline Staining & 11 & 11 & 8 & 3 & 0 & 0 & 0 \\
\hline Cloudiness & 10 & 10 & 10 & 8 & 6 & 5 & 5 \\
\hline Vascularisation & 0 & 0 & 0 & 0 & 1 & 1 & 4 \\
\hline Clinical cure - & $-0 / 11$ & $0 / 11$ & $0 / 11$ & $2 / 11$ & $3 / 11$ & $5 / 11$ & $4 / 11$ \\
\hline
\end{tabular}

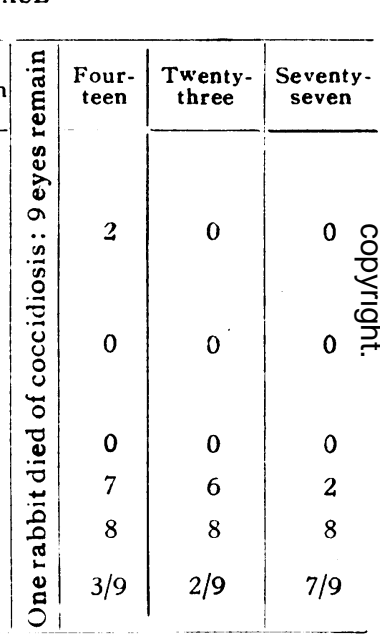

tap water and cotton wool swabs. Staining of the cornea with fluorescein to observe the course of epithelial ulceration was the only other form of interference. Observations were made every few minutes at first, then at about three hourly intervals on the day of application. After this the rabbits were examined daily for ten days, then on alternate days for two weeks and finally about once a week for twelve weeks. Some details of the reaction of each eye are set forth in Table I.

The cornea was especially examined for size and duration of staining areas, and for alterations in the substantia propria, particularly oedema and vascularisation, which proved to be characteristic and peculiar. We intend to describe these signs in detail in a later paper. 
In spite of the smallness of the lesions and care in keeping the lids open, a slight amount of conjunctival hyperaemia and discharge occurred in the majority of eyes, but the lids were never much swollen and there was no difficulty in detailed examination. After 24 hours this conjunctivitis was present in nine out of eleven eyes, and decreased after the second day, only three out of eleven showing it at the end of a week, and in these it was very slight.

All the corneae stained immediately at the site of application over varying areas. We have come to consider that the area of initial staining is proportional to the size of the dose and is of prognostic value. The staining disappears in all after the fourth day, in spite of the fact that the corneal condition continues to get worse for long after this. The staining is accompanied by varying degrees of oedema of the substantia propria which subsides slowly for a week and then increases in the majority of eyes and may persist over the whole period of observation (more than three months). From the fifth day onwards vessels begin to invade the oedematous area and increase in number and length for several weeks. The final stages of this process have not yet been seen in all eyes; clinical cure (subsidence of oedema and quiescence of vessels) occurs in about half the eyes at the end of a week but does not always appear to be permanent, relapses being frequent.

The severity and persistence of the corneal lesion is surprising in view of the minute quantity of mustard gas applied, and the apparently quiet condition of the eye as a whole to macroscopic examination.

\section{Experiment II. See Table II}

\section{Application of a minute unmeasured dose of liquid mustard gas in rabbits treated with ascorbic acid}

On April 6, 1940, twelve eyes of six young blue- and browneyed rabbits were treated with mustard gas in exactly the same way as in Exp. I and $500 \mathrm{mgs}$. of ascorbic acid were injected 20 minutes before treatment and daily for the following five days. Six doses were given in all, some intravenously as ascorbic acid, and some into the peritoneum immediately after neutralisation with sodium hydroxide. Ascorbic acid itself was so badly tolerated by the rabbits that its use was given up after the fourth dose. On enquiring from Livingston and Walker, it was found that the acid had been neutralised before injection in their experiments. The test was therefore repeated in Exp. III, using a stable solution (Celin Forte) provided by Glaxo Laboratories. Nevertheless all the six rabbits in Exp. II received the whole dose 
either as acid or in freshly made neutral solution and we consider our results are valid. No further treatment was given. In this group the same proportion of eyes (about half) recovered rapidly (in a week) after only slight damage (Table II) while in others the long-continued series of severe pathological changes described

Table II. Experiment II. Mustard Gas and Ascorbic Acid Figures refer to number of eyes affected out of 12

\begin{tabular}{|c|c|c|c|c|c|c|c|c|c|c|c|}
\hline \multirow{2}{*}{\multicolumn{2}{|c|}{ LESIONS }} & \multicolumn{10}{|c|}{ DAYS OF DISEASE } \\
\hline & & One & Two & Three & Four & Five & Six & Eight & Twelve & $\begin{array}{c}\text { Twenty- } \\
\text { two }\end{array}$ & Eighty \\
\hline \multicolumn{2}{|c|}{$\begin{array}{l}\text { Conjunctivitis with } \\
\text { or without muco- } \\
\text { purulent discharge }\end{array}$} & 9 & 8 & 6 & 5 & 4 & 6 & 6 & 3 & 1 & 1 \\
\hline \multicolumn{12}{|c|}{$\begin{array}{l}\text { Swelling (hyperae- } \\
\text { mia and oedema) of }\end{array}$} \\
\hline lids $\quad-\quad-$ & - & 6 & 4 & 5 & 1 & 2 & 1 & 3 & 0 & 0 & 0 \\
\hline \multicolumn{12}{|l|}{ CORNEA: } \\
\hline Staining & - & 12 & 11 & 3 & 1 & 0 & 0 & 0 & 0 & 0 & 0 \\
\hline Cloudiness & - & 12 & 12 & 12 & 12 & 5 & 7 & 6 & 9 & 11 & 8 \\
\hline Vascularisation & - & 0 & 0 & 0 & 0 & 0 & 2 & 3 & 9 & 10 & $10^{\circ}$ \\
\hline Clinical cure - & - & $0 / 12$ & $0 / 12$ & $0 / 12$ & $0 / 12$ & $6 / 12$ & $7 / 12$ & $5 / 12$ & $6 / 12$ & $1 / 12$ & $3 / 12$ \\
\hline
\end{tabular}

in Exp. I developed and continued in the same way for three months. In both series the eyes which recovered rapidly were those suspected of having accidently received a smaller dose. Suspicion was based on variation in staining area of the corneal epithelium. This suspicion was confirmed in another series of eyes by using the same applicator, but a chemical which produced an instantaneous white coagulum. The size of the injured area could thus be seen immediately and was found to vary considerably, however carefully the application was made.

\section{Experiment III. SeE TABLE III}

\section{Application of an accurately measured dose of liquid mustard} gas in rabbits treated with neutralised ascorbic acid

Since the foregoing experiments formed a test of the effect of ascorbic acid on the application of mustard gas to the cornea alone, further experiments were done in order to repeat those of 
Livingston and Walker as closely as possible. Large rabbits as nearly as possible comparable to theirs were obtained from the same source. The same sample of mustard gas supplied to Livingston and Walker was used throughout all our work. The ascorbic acid was obtained ready neutralised in sealed ampoules from Glaxo Laboratories. The same dose and number of doses was given intravenously. The applicator, a Pasteur pipette drawn out to a fine point, was supplied by one of the Glaxo Laboratory Staff who also described their technique in detail and examined the rabbits beforehand and also on the sixth day of the experiment.

Particular care was taken to deliver exactly the same dose to each eye. The liquid mustard gas was put into a small specially made stoppered glass container. Two horizontal scratches were made on the outside of the glass mustard gas container to correspond with a particular column of water in the Pasteur pipette. In drawing up the liquid mustard gas the tip of the pipette was drained against the inside of the container opposite the scratches in order to adjust the column in the pipette to the length between the scratches. Binocular loupe spectacles were used to attain accuracy. Except in the case of one eye, in which a small part of the column was seen within the pipette after delivery, all eyes received an identical dose. The weight of the same length column of distilled water at $21^{\circ} \mathrm{C}$. was $0.0005 \mathrm{gm}$. on a balance weighing to the fourth decimal point. This dose, (approx. 0.0005 c.c.) was much less than the maximum ( 0.075 c.c.) given by Livingston and Walker. Our dose was chosen and considered sufficient on the basis of reports by Warthin, Weller and Hermann. ${ }^{2}$ These authors delivered 0.0004 c.c. and caused lesions (of which they made sections) severe enough for the purpose of testing any therapeutic agent. In our experiment the rabbit was held on its side and the eyelids held open for about two minutes and then allowed free. The rabbits did not always blink immediately. The eyes were examined and cleaned up daily with boiled tap water and cotton wool swabs. No other treatment was given. The amount of reaction produced was intense. Detailed examination of the cornea in the early stages was impossible owing to swelling of lids and conjunctivae. Swelling, hyperamia and oedema of lids and conjunctivae, and mucopurulent discharge were very great. See Table III. On the seventh day the condition was as follows : lids and conjunctivae of eight eyes were swollen, hyperaemic and oedematous; lids of seven were closed and stuck together by mucopurulent discharge; one eye, which received the incomplete dose recorded above was half open, but discharge was present; the substantia 
propria was affected in eight. (cf. Table III, Livingston and Walker).* By the twenty-first day all corneae had vascularised. The animals remained in excellent general condition throughout.

TAble III. Experiment III. Mustard Gas and Ascorbic ACid Figures refer to number of eyes affected out of 8

\begin{tabular}{|c|c|c|c|c|c|c|c|c|c|}
\hline \multirow{2}{*}{ LESIONS } & \multicolumn{9}{|c|}{ Days of Disease } \\
\hline & One & Two & Three & Four & Five & Six & Seven & $\begin{array}{l}\text { Four- } \\
\text { teen }\end{array}$ & $\begin{array}{c}\text { Twent } \text { T }^{-} \\
\text {one }\end{array}$ \\
\hline $\begin{array}{l}\text { Conjunctivitis with } \\
\text { mucopurulent dis- } \\
\text { charge - }\end{array}$ & 8 & 8 & 8 & 8 & 8 & 8 & 8 & 8 & 7 \\
\hline $\begin{array}{l}\text { Swelling (hyperae- } \\
\text { mia and oedema) of } \\
\text { lids - }\end{array}$ & 8 & 8 & 8 & 8 & 8 & 8 & 8 & 6 & 4 \\
\hline CORnEA: & & & & & & & & & \\
\hline Staining* & - & - & - & - & - & - & - & 1 & 1 \\
\hline Cloudiness - & 8 & 8 & 8 & 8 & 8 & 8 & 8 & 8 & 8 \\
\hline Vascularisation & 0 & 0 & 0 & 0 & 0 & 0 & 0 & 5 & 8 \\
\hline Clin ical cure - & $0 / 8$ & $0 / 8$ & $0 / 8$ & $0 / 8$ & $0 / 8$ & $0 / 8$ & $0 / 8$ & $0 / 8$ & $0 / 8$ \\
\hline
\end{tabular}

This evidence shows that neither a small dose of liquid mustard gas on the cornea alone nor a large one spread over cornea, lids and conjunctivae, is prevented, by $500 \mathrm{mgs}$. daily of ascorbic acid, from causing typical lesions at the sites the liquid reaches. The progress of the lesions is not affected in any way which we could detect, nor does the severity of the lesion vary from rabbit to rabbit. The apparent variability of Livingston and Walker's results, attributed by them to natural resistance in some animals, is probably due to difference in dosage. Our own experiments showed that the same applicator did not always transfer the same dose. A definite measured volume must be expelled from the same pipette each time to get comparable lesions.

\section{Conclusions}

1. Intravenous injections of ascorbic acid do not prevent nor influence the progress of mustard gas lesions of lids, conjunctivae or cornea.

* On the sixth day the animals were examined by a member of the Glaxo Laboratories Staff who had seen Livingston and Walker's experiments. He did not consider that the treatment with ascorbic acid had modified the lesion. 
2. The degree of damage is related to the dose and is not influenced by resistance of individual animals to the chemical. Identical doses produce almost identical lesions.

We have much pleasure in expressing thanks to the Council of the Imperial Cancer Research Fund for its generous help in providing laboratory and equipment for this work; to Messrs. Glaxo for supplies of ascorbic acid and of animals; to Mr. H. G. Crabtree for instruction on the chemical and physical properties of mustard gas; to Group Captain P. C. Livingston and Flight Lieutenant $H$. M. Walker for their invitation to continue the work and their whole-hearted co-operation.

\title{
REFERENCES
}

1. Livingston, P. C. and Walker, H. M.-Brit. Jl. Ophthal., p. 67, February, 1940.

2. Warthin, A. S., Weller, C. V. and Hermann, G. R.-Jl. Lab and Clin. Med., Vol. IV, p. 785, 1919.

\section{BOECK'S SARCOIDOSIS OF THE LACRYMAL GLAND}

BY

\author{
H. B. Stallakd \\ R.A.M.C.
}

THE terms lupus pernio, Besnier-Boeck's disease, Boeck's sarcoidosis, and Shaumann's benign lymphogranuloma are synonyms for a disorder of parts of the reticulo-endothelial system characterised by nodular lesions composed of a central mass of endothelial cells surrounded by a fringe of lymphocytes and, very rarely, a giant cell of the Langhans type. Caseation is never seen in these lesions, tubercle bacilli are not evident in specially stained sections, and inoculation of material from these nodules into a guinea-pig gives a negative result.

Some authors have suggested that this disease and uveoparotitis are a tuberculous or so-called para-tuberculous manifestation, but there seems to be no definite clinical or experimental evidence to support this conception. Syphilis has also been blamed, but without good reason. However, the cause of this disease remains so far unknown. On histological grounds it appears to belong to a group of disorders of the reticulo-endothelial system in which may be included uveoparotitis (Heerfordt), lymphadenoma (Hodgkin), 